\title{
Intervention Study to Upgrade Patient Safety Practices in Pediatric Intensive Care Units of Cairo University Children Hospital
}

\author{
Mona Adel Soliman ${ }^{1}$, Amira Aly Hegazy ${ }^{1}$, Hafez Mahmoud Bazaraa ${ }^{2}$, Nargis Albert ${ }^{1}$, Hend Aly Sabry ${ }^{1 *}$ \\ ${ }^{1}$ Public Health and Community Medicine Department, Cairo University, Egypt; ${ }^{2}$ Pediatric Department, Cairo University, Egypt
}

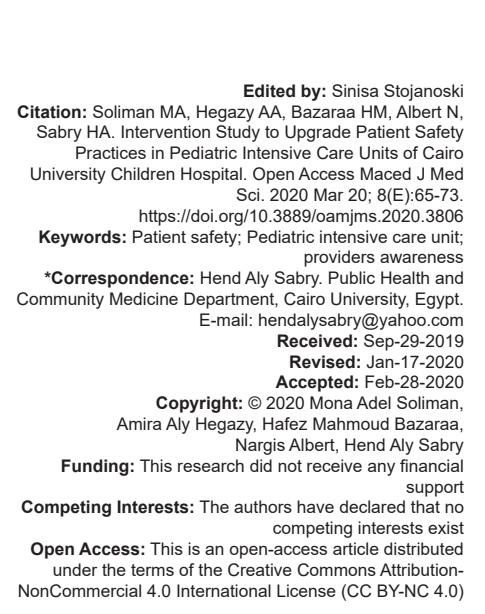

\section{Background}

To expect a flawless performance from humans working in complex and stressful environments is impossible, and will not improve safety [1]. Humans are protected from making errors when placed in an environment where the systems and processes they work in are well planned [2]. Accordingly, concentrating on the system that permits harm to occur by emphasizing the reporting, analysis, and prevention of medical error is the beginning of improvement. Recognizing that patient safety failures are among the 10 leading causes of death and disability in the world, the World Health Organization (WHO) calls patient safety "an endemic concern" [3]. Knowing that errors that were once perceived as unavoidable have now become preventable and open to mitigation, keeping patients safe is now viewed as a global public health problem and a human rights issue [4].

One of the biggest challenges facing healthcare professionals is how to best match, prioritize, and implement effective and evidence-based safety interventions that are measurable, reliable, and relevant [5]. This can only occur in an open and transparent environment where a safety culture prevails, which is considered the biggest obstacle to improve patient safety [6]. This is a culture where a huge substance is placed on safety beliefs, values, and attitudes that are shared by people within the workplace [7]. Assessment of safety culture in a given institution helps to inform the perceptions and behaviors of administrators regarding safety as well as identify the most problematic areas for improvement [8].

While most attempts to improve safety in health care are reactive, proactive efforts to identify, prevent, and eliminate errors have the potential to significantly improve safety. To accomplish this, patient safety must be viewed as a strategic priority around which the entire efforts of the organization must be focused in a multidisciplinary approach involving everyone working as a team, supported by a safety culture [9].

Nowhere in the hospital is a greater challenge than the pediatric intensive care unit (PICU), as PICUs are high-hazard and -risk environments because of the heterogeneity of patients, their complexity and severity and the difficulty of the work and tools required to care for these patients. The fact that more opportunities to 
prevent harm are not yet identified in PICUs may be explained by the limited detection methods [10].

Patient safety has been marked as a key priority of health care in recent decades not only because of the recognition of the extent and severity of the problem, but equally because of the demonstration that successful interventions can reduce, mitigate, or prevent known harm [4]. Thus, the aim of this study is to enhance compliance to patient safety practices and outcomes within the general PICUs in Cairo University Children's Hospital which is an around the clock institute providing pediatric patients with all kinds of care, it is also a research and teaching hospital, through applying a tailored patient safety program.

\section{Methods}

\section{Study design and study setting}

The current study is an intervention study, a pretest-posttest design, in which an initial assessment of health-care providers' patient safety knowledge, attitude, and practices was conducted within the four general PICUs of Cairo University tertiary teaching children hospitals which all have similar organizational and staffing structures. A tailored intervention according to the results of the baseline assessment was designed and implemented, and then, the patient safety situation was reassessed to detect the changes that occurred after the intervention. The intervention included patient safety education training, the training sessions were designed with the collaboration of the hospital quality team using PowerPoint presentations about patient safety definition, overview, goals, and safety culture, including the causes of errors, and incident reporting of "near misses," based on the WHO patient safety curriculum guide [11].

Furthermore, posters were hung in the healthcare providers' rooms, in addition to hand-outs, pocket leaflets, and badges as key tools to prompt and remind health care workers about the importance of patient safety and about the appropriate indications and procedures for performing it.

The training sessions were interactive and conducted for small groups inside the ICUs during their working day. A total of 12 sessions, three in each ICU, each about $30 \mathrm{~min}$ in addition to $15 \mathrm{~min}$ for open questions and discussion, were done over a period of 8 weeks.

Health-care personnel were tested for patient safety knowledge immediately after each training session and the test was collected in $15 \mathrm{~min}$. After the assessment, each of the personnel was awarded a badge with the name and logo of "Patient Safety," written in English and Arabic.

\section{Study population and sampling}

All physicians and nursing staff present in the general PICUs of Cairo University Children Hospital who were available and consented to participate in the study at the time of the research.

Seventy-three out of 96 health-care providers; 20 physicians and 53 nurses were included in the baseline assessment, intervention, and end line assessment phases of the study, making the response rate around $76 \%$, refusals were because of work overload.

\section{Data collection tools}

A designed self-administered questionnaire was formulated of seven questions to assess the health-care providers' knowledge about patient safety definition, concept, and patient safety goals basic knowledge.

This tool was translated into Arabic and back translated into English to ensure consistency with the original English version. The questionnaire was adapted to fit the Egyptian context to suit the culture in our hospitals and its items and questions were verified to be clear and comprehensive through pilot testing. Validation of the adapted and translated study tool was conducted before using it for data collection. The correct answer was scored as 1 and the wrong answer was scored as 0 with maximum possible total score of 7 .

A Safety Attitudes Questionnaire (SAQ) was adopted to assess patient safety attitude of the study participants. These SAQ items were developed with the goal of obtaining a staff level perspective on patient safety in hospital setting and can be used to track changes in patient safety overtime and to evaluate the impact of patient safety interventions [8], [12]. The Arabic version of a previous study performed in Oman with Cronbach's alpha value of 0.97 was used [13].

It included the following safety culture dimensions; non-punitive response to error (one item), hospital Handoffs and transitions (one item), staffing and workload (6 items), feedback and communication about error (one item), management perception for patient safety (5 items), teamwork climate in hospital (2 items), overall perceptions of safety (2 items), interactions and communication in ICU (5 items), communication openness (3 items), incident reporting (3 items), organizational learning-continuous improvement (2 items), safety climate (6 items), teamwork climate in ICU (2 items), and job satisfaction (3 items). Five-point Likert response scale agreement (strongly disagree to strongly agree) was used. Grouping of the responses was done as follows: Positive responses for strongly agree and agree responses, neutral response for neither, and negative responses for strongly disagree and disagree responses. Reversal of the direction of the responses was done in negative wording questions. 
A patient safety performance checklist was used to assess the PICUs health personnel's compliance based on the Joint Commission International $(\mathrm{JCl})$ Accreditation Standards for Hospitals' patient safety standards after removing the items related to outpatient clinics and patient safety goal 4 , which is related to surgical safety to fit the checklist to PICUs environment. The used checklist composed of five standards related to the international patient safety goals, and each goal had three measurable elements as follows: Goal 1: Identify patients correctly, Goal 2: Improve effective communication, Goal 3: Improve the safety of highalert medications, Goal 5: Reduce the risk of health care-associated infections, and Goal 6: Reduce the risk of patient harm resulting from falls.

Twelve observations (three observations in each ICU) were undertaken by one of the researchers in the pre-assessment and then another 12 in the post-assessment. The observer did her best to position herself so that she does not cause an obstruction and can still see what is happening. The elements are scored as "met" $=2$, "partially met" $=1$, or "not met" $=0$, making the maximum possible total score for each goal equal 6 . The average of the 12 performed observations for each of the pre- and post-assessments was taken.

\section{Data analysis}

Data were summarized using number and percentages for qualitative variables, median and interquartile range (IQR) were used for quantitative variables.

Comparison of numerical variables between the study groups was done using Mann-Whitney U-test for independent samples when comparing two groups and Kruskal-Wallis test when comparing more than two groups. Comparison between pre- and postprogram was done using McNemar test for qualitative variables and Kruskal-Wallis test for numerical variables. $p<0.05$ was considered statistically significant.

\section{Ethical considerations}

The used questionnaire was anonymous and voluntary. Verbal consent was obtained from all participants before recruitment in the study, after explaining the objectives of the work. Confidentiality was guaranteed on handling the data base and questionnaire forms. The researcher treated the healthcare providers according to the Helsinki Declaration of biomedical ethics. The researcher obtained administrative approvals from the hospital and PICUs' managers. The study was approved by the public health and the pediatric departments of Faculty of Medicine, Cairo University.

\section{Results}

The total number of health-care personnel who participated in the study was $73,69.9 \%$ of them were female. The median of their age was 30 and IQR 28-40. There was almost equal involvement of healthcare personnel representing $24.7 \%$ from ICUs A, B, and $C$ and $26.0 \%$ from ICU D. The majority of the included personnel were 45 nurses, representing $61.6 \%$ of the total personnel. More than half (43) of the included personnel have been working in the hospital from 1 to 15 years before the study, $64.4 \%$ of the personnel worked on a full-time basis. The vast majority $(95.8 \%)$ said that they worked more than $8 \mathrm{~h} /$ day.

On comparing the patient safety knowledge among females and males, as shown in Table 1, no

Table 1: Relation between total knowledge score and sociodemographic and occupational characteristics among the studied health-care personnel

\begin{tabular}{|c|c|c|}
\hline Item & Knowledge score median (IQR) & $\mathrm{p}$-value \\
\hline \multicolumn{3}{|l|}{ Sex } \\
\hline Female & $3.0(3.00-4.00)$ & \multirow[t]{2}{*}{0.097} \\
\hline Male & $3.0(3.00-4.00)$ & \\
\hline \multicolumn{3}{|l|}{ ICU } \\
\hline A & $3.0(3.00-3.75)$ & \multirow[t]{4}{*}{0.530} \\
\hline B & $3.5(3.25-4.00)$ & \\
\hline C & $3.0(3.00-3.75)$ & \\
\hline D & $3.0(3.00-4.00)$ & \\
\hline \multicolumn{3}{|c|}{ Duration of work in the hospital (years) } \\
\hline$<1$ & $3.0(3.00-4.00)$ & \multirow[t]{5}{*}{0.154} \\
\hline $1-5$ & $3.25(3.00-4.00)$ & \\
\hline $6-10$ & $3.0(3.00-3.75)$ & \\
\hline $11-15$ & $3.0(3.00-4.00)$ & \\
\hline$>15$ & $2.75(2.50-3.75)$ & \\
\hline \multicolumn{3}{|l|}{ Job title } \\
\hline Staff physician & $3.0(2.75-4.00)$ & \multirow[t]{4}{*}{0.121} \\
\hline Head nurse & $3.0(3.00-4.00)$ & \\
\hline Resident physician & $3.0(3.00-3.75)$ & \\
\hline Nurse & $3.0(3.00-4.00)$ & \\
\hline \multicolumn{3}{|l|}{ ICU job status } \\
\hline Full time & $3.0(3.00-4.00)$ & \multirow[t]{3}{*}{0.727} \\
\hline Part time & $3.0(3.00-4.00)$ & \\
\hline On contract & $2.75(3.00-3.75)$ & \\
\hline \multicolumn{3}{|c|}{ Average weekly working hours (hours) } \\
\hline $20-39$ & $3.0(3.0-3.0)$ & \multirow[t]{3}{*}{0.345} \\
\hline $40-79$ & $3.0(3.0-4.0)$ & \\
\hline$\geq 80$ & $3.0(3.0-4.0)$ & \\
\hline \multicolumn{3}{|c|}{ Perceived patient safety grade } \\
\hline Excellent & $3.0(3.00-4.00)$ & \multirow[t]{4}{*}{0.964} \\
\hline Very good & $3.0(3.00-4.00)$ & \\
\hline Acceptable & $3.0(3.00-4.0)$ & \\
\hline Poor & $3.0(3.00-3.75)$ & \\
\hline \multicolumn{3}{|c|}{ Previous patient safety training } \\
\hline Yes & $6.0(6.0-7.0)$ & \multirow[t]{2}{*}{$<0.001$} \\
\hline No & $3.0(3.0-4.0)$ & \\
\hline
\end{tabular}

statistically significant difference was found between them, so was among the studied ICUs, the duration of work in the hospital, job title, ICU job status, and their perceived patient safety grade. However, there was a statistically significant difference between those who received patient safety training and those who did not.

The box plot shown in Figure 1 expresses the change in total knowledge score before and after the intervention among the health-care personnel. The median total knowledge score was significantly increased from 3 and IQR (3.0-4.0) in the preassessment to 6 and IQR (5.0-7.0) post-assessment with $p=0.01$. 


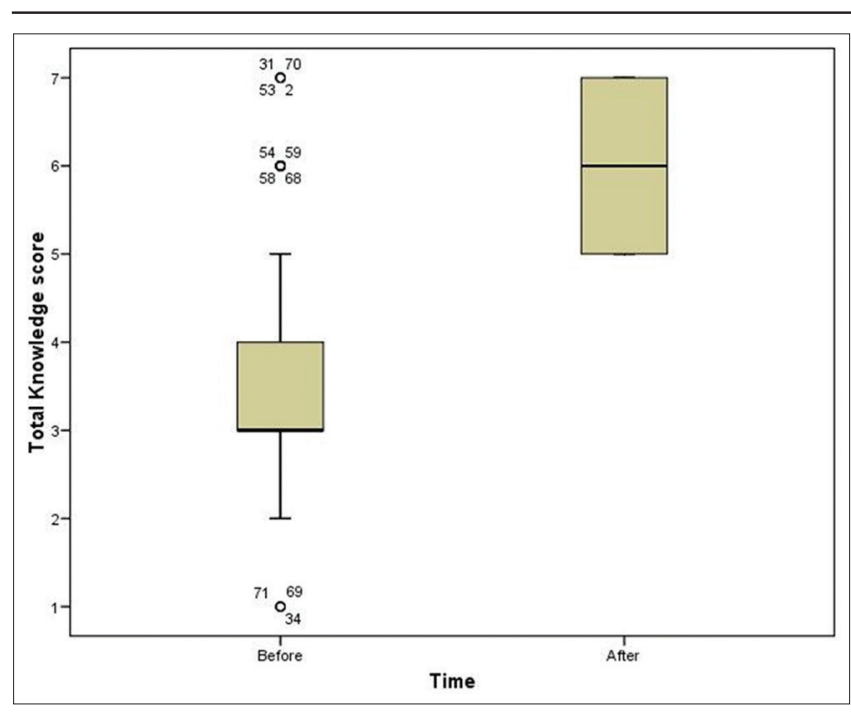

Figure 1: Effect of the intervention on the total patient safety knowledge

Tables 2 and 3 display the change in the attitude of the studied personnel regarding their perception to patient safety culture's dimensions before and after the intervention, where there was no statistically significant difference in the dimensions of "Job Satisfaction, Teamwork Climate in ICU, Teamwork climate in hospital, Staffing and workload, Hospital handoffs and transitions, Organizational learning continuous improvement, Feedback and communication about errors, and Non-punitive response to errors" and a statistically significant improvement in some items under the dimensions of "Safety Climate, Management Perception toward patient safety, Interactions and Communication in the ICU, Communication openness, and Incident reporting." However, the dimension of "Overall perception of Patient Safety" showed a statistically significant decrease.

Table 4 shows the change in the achievement scores of patient safety goals in the studied PICUs between the baseline and end line assessment, where there was a statistically significant difference in all goals except for goal 6 which showed no change.

\section{Discussion}

Research indicates, however, that health-care systems face a big challenge to ensure safe care for patients and prevent harm. Thus, it is important to identify the weakest areas in the knowledge of healthcare professionals. By doing so, we may create the best strategy to increase the level of knowledge, to achieve safer clinical practice [14].

On looking more in depth in the total knowledge scores of the studied participants, no statistically significant relation was found between their patient safety knowledge and their demographic and background characteristics, including sex, job title, years of experience, specific ICU, ICU job status, or weekly working hours, which comes in accordance with de Oliveira et al. and showing the homogeneity of the four PICUs, which have the same organizational and staffing structure [15].

However, there was a statistically significant difference between those who received previous patient safety training prior to the study and those who did not

Table 2: Frequency of patient safety attitude's positive responses in the pre- and post- assessments regarding job satisfaction, teamwork climate, staffing, and safety among the studied health-care personnel

\begin{tabular}{|c|c|c|c|c|c|c|}
\hline \multirow[t]{3}{*}{ Patient safety culture dimensions } & \multirow[t]{3}{*}{ Item } & \multicolumn{4}{|c|}{ Positive responses } & \multirow[t]{3}{*}{$\mathrm{p}$-value } \\
\hline & & \multicolumn{2}{|c|}{ Pre-assessment } & \multicolumn{2}{|c|}{ Post-assessment } & \\
\hline & & $\mathrm{n}$ & $\%$ & $\mathrm{n}$ & $\%$ & \\
\hline \multirow[t]{3}{*}{ Job satisfaction } & I like my job & 59 & 80.8 & 62 & 84.9 & 0.125 \\
\hline & I am proud to work in this hospital & 65 & 89 & 67 & 91.8 & 0.157 \\
\hline & Morale in this ICU is high & 58 & 79.5 & 60 & 82.2 & 0.346 \\
\hline \multirow[t]{2}{*}{ Teamwork climate in ICU } & I get the support I need from other personnel to care for patients & 54 & 74.0 & 55 & 75.3 & 1 \\
\hline & The physicians and nurses here work together as a well-coordinated team & 43 & 58.9 & 46 & 63.0 & 0.125 \\
\hline \multirow[t]{2}{*}{ Teamwork climate in hospital } & When this unit gets really busy, other units help out & 38 & 52.1 & 35 & 47.9 & 0.346 \\
\hline & There is good cooperation among hospital units that need to work together & 26 & 35.6 & 23 & 31.5 & 0.176 \\
\hline \multirow[t]{6}{*}{ Staffing and workload } & The level of staffing in this PICU is enough to handle the number of patients & 20 & 27.4 & 19 & 26.0 & 1 \\
\hline & New personnel are trained well and are adequately supervised in this ICU & 23 & 31.5 & 23 & 31.5 & \\
\hline & High levels of workload are common in this PICU & 20 & 27.4 & 17 & 23.3 & 0.176 \\
\hline & $\begin{array}{l}\text { Fatigue impairs my performance during routine care (e.g., ventilator checks, medication } \\
\text { reviews, transfer orders) }\end{array}$ & 22 & 30.1 & 24 & 32.9 & 0.346 \\
\hline & Fatigue impairs my performance in emergency situations & 40 & 54.8 & 39 & 53.4 & 1 \\
\hline & $\begin{array}{l}\text { During emergency situations (e.g., emergency resuscitation), my performance is not affected } \\
\text { if I work with inexperienced or less capable personnel }\end{array}$ & 39 & 53.4 & 39 & 53.4 & \\
\hline \multirow[t]{6}{*}{ Safety climate } & I would feel safe being treated here as a patient & 31 & 42.5 & 35 & 47.9 & 0.376 \\
\hline & Physicians/intensivist in this ICU are doing a good job & 62 & 84.9 & 65 & 89 & 0.514 \\
\hline & $\begin{array}{l}\text { Personnel know the rules or guidelines (e.g., handwashing, sterile fields, treatment } \\
\text { protocols) established in this ICU }\end{array}$ & 45 & 61.6 & 52 & 71.2 & 0.003 \\
\hline & $\begin{array}{l}\text { There is widespread adherence to clinical guidelines and evidence-based rules (e.g., } \\
\text { handwashing, sterile fields, treatment protocols) established in this ICU }\end{array}$ & 43 & 58.9 & 41 & 56.2 & 0.125 \\
\hline & All the personnel in this unit take responsibility for patient safety & 40 & 54.8 & 52 & 71.2 & $<0.001$ \\
\hline & The medical equipment in this ICU is adequate & 60 & 82.2 & 60 & 82.2 & \\
\hline \multirow{5}{*}{$\begin{array}{l}\text { Management perception toward } \\
\text { patient safety }\end{array}$} & Patient safety is constantly reinforced as a priority in this ICU & 35 & 47.9 & 64 & 87.7 & $<0.001$ \\
\hline & Hospital management provides a work climate that promotes patient safety & 40 & 54.8 & 46 & 63.0 & 0.030 \\
\hline & Hospital management does not knowingly compromises the safety of patients & 31 & 42.5 & 38 & 52.1 & 0.046 \\
\hline & This hospital deals constructively with problem personnel & 19 & 26.0 & 18 & 24.7 & 1 \\
\hline & Hospital management supports my daily efforts & 25 & 34.2 & 27 & 37.0 & 0.514 \\
\hline \multirow[t]{2}{*}{ Overall perception of patient safety } & I have made errors that had the potential to harm patients & 38 & 52.1 & 31 & 42.5 & 0.030 \\
\hline & I have seen others make errors that had the potential to harm patients & 11 & 15.0 & 9 & 12.3 & 0.317 \\
\hline
\end{tabular}


Table 3: Frequency of patient safety attitude's positive responses in the pre- and post- assessments regarding communication, organizational learning continuous improvement, and errors' culture among the studied health-care personnel

\begin{tabular}{|c|c|c|c|c|c|c|}
\hline \multirow[t]{3}{*}{ Patient safety culture dimensions } & \multirow[t]{3}{*}{ Item } & \multicolumn{4}{|c|}{ Positive responses } & \multirow[t]{3}{*}{ p-value } \\
\hline & & \multicolumn{2}{|c|}{ Pre-assessment } & \multicolumn{2}{|c|}{ Post-assessment } & \\
\hline & & $\mathrm{n}$ & $\%$ & $\mathrm{n}$ & $\%$ & \\
\hline Interactions and communication in & Interactions in this ICU are collegial more than hierarchical & 34 & 46.6 & 36 & 49.3 & 0.476 \\
\hline \multirow{4}{*}{ the ICU } & I receive appropriate feedback about my performance & 31 & 42.5 & 36 & 49.3 & 0.125 \\
\hline & Decision-making in this ICU utilize input from relevant person & 36 & 49.3 & 36 & 49.3 & \\
\hline & All the necessary diagnostic and therapeutic information are available to me & 39 & 53.4 & 37 & 50.7 & 0.514 \\
\hline & I know the appropriate channels to direct questions regarding patient safety in this unit & 21 & 28.8 & 51 & 69.9 & $<0.001$ \\
\hline Hospital handoffs and transitions & Disruptions in patient care (e.g., patient transfer) can be detrimental to patient safety & 14 & 19.2 & 18 & 24.7 & 0.157 \\
\hline Organizational learning continuous & The culture of this ICU makes it easy to learn from the errors of others & 25 & 34.2 & 30 & 41.1 & 0.176 \\
\hline improvement & In this unit, it is difficult to discuss errors & 58 & 79.5 & 66 & 90.4 & $<0.001$ \\
\hline \multirow[t]{3}{*}{ Communication openness } & $\begin{array}{l}\text { It is easy for personnel in this ICU to ask questions when there is something they do not } \\
\text { understand }\end{array}$ & 54 & 74.0 & 60 & 82.2 & 0.073 \\
\hline & I am encouraged by my colleagues to report any patient safety concerns I may have & 51 & 69.9 & 60 & 82.2 & 0.046 \\
\hline & Staff will freely speak up if they see something that may negatively affect patient care & 34 & 46.6 & 51 & 69.9 & $<0.001$ \\
\hline $\begin{array}{l}\text { Feedback and communication about } \\
\text { errors }\end{array}$ & $\begin{array}{l}\text { I am provided with adequate, timely information about events in the hospital that might affect } \\
\text { my work }\end{array}$ & 28 & 38.4 & 30 & 41.1 & 0.514 \\
\hline Non-punitive response to errors & $\begin{array}{l}\text { When an error is made in this PICU, it is handled appropriately (i.e., not who is right, but } \\
\text { what is right for the patient) }\end{array}$ & 15 & 20.6 & 19 & 26.0 & 0.25 \\
\hline \multirow{3}{*}{ Incident reporting } & If necessary, I know how to report errors that happen in this ICU & 27 & 37.0 & 59 & 80.8 & $<0.001$ \\
\hline & $\begin{array}{l}\text { A confidential reporting system that documents medical incidents is necessary for improving } \\
\text { patient safety }\end{array}$ & 44 & 60.3 & 70 & 95.9 & $<0.001$ \\
\hline & I would hesitate to use the reporting system for fear of being identified & 47 & 64.4 & 70 & 95.9 & $<0.001$ \\
\hline
\end{tabular}

Table 4: Total achievement scores of patient safety goals in the pediatric intensive care units according to the joint commission international patient safety standards in the preand post-assessments

\begin{tabular}{lll}
\hline Goals & Median (IQR) & p-value \\
\hline Goal 1 (patient identification) & $3.00(2.00-3.00)$ & 0.046 \\
$\quad$ Pre & $4.00(4.00-4.00)$ & \\
$\quad$ Post & $2.00(1.00-2.00)$ & 0.035 \\
Goal 2 (communication) & $2.50(2.00-3.00)$ & \\
$\quad$ Pre & $2.50(2.00-3.00)$ & 0.020 \\
$\quad$ Post & $3.00(3.00-3.75)$ & \\
Goal 3 (medication safety) & & \\
$\quad$ Pre & $4.00(4.00-4.75)$ & \\
$\quad$ Post & $5.00(4.00-5.00)$ & \\
Goal 5 (health-care acquired infections) & \\
$\quad$ Pre & $2.00(1.00-2.00)$ & \\
$\quad$ Post & $2.00(1.00-2.00)$ & \\
Goal 6 (falls prevention) & & \\
$\quad$ Pre & & \\
$\quad$ Post &
\end{tabular}

with $p<0.001$, similar to the findings by the Ethiopian study by Wami et al. to study health care workers' view on patient safety culture and its related factors [16].

Introducing the concept of patient safety to the health-care personnel was crucial being relatively new for most of them, as shown in the results of the baseline assessment, with the median score was 3.0 and IQR (3.0-4.0).

The studies on health-care professionals knowledge levels yielded contradictory results. Some studies reported a good knowledge level [17], yet others identified knowledge deficits [18], [19].

In the study intervention, patient safety goals and standards were clear and focused on and were communicated clearly in the training sessions, which is vital to any patient safety training program. In addition to relying on local clinical leadership, using multiple strategies to gain support of staff and sharing learning and solutions with health-care personnel that helped create more momentum [20], [21]. This helped the health-care personnel's knowledge to significantly improve in all of the questioned items and in the overall patient safety knowledge score, where the median total knowledge score before the training was 3 and IQR 3.0-4.0, while after the training, it was 6 and IQR 5.0-7.0, where there was a statistically significant difference between the results in the pre-assessment and post-assessment, with $p=0.01$.

Similar findings were discovered in another study by El-Sayed et al., where statistically significant knowledge improvement was found in the general aspects of patient safety [19].

The results of the present study revealed that the overall patient safety grade was rated acceptable by $53.4 \%$ of the interviewed subjects. A similar result was found by Aboul-Fotouh et al. in a study in Ain Shams University to assess patient safety culture, where $57.3 \%$ of the participants found it acceptable [22].

However, it came in contrast to the overall patient safety grade in a similar study done in Saudi Arabia by Alahmadi, where $33 \%$ of the respondents found it to be acceptable. Still, the Saudi study had a few limitations, where the data used were from 13 hospitals and merged in the analysis despite the fact that these institutions were variable in terms of size, complexity, and focus on patient safety [23].

In the current study, the highest dimension of patient safety in this current study was job satisfaction among the participants of this study with $83.1 \%$, which is similar to the Palestinian study, where job satisfaction area received the highest safety attitude area with $71.2 \%$ of positive responses.

While, the lowest dimension in the patient safety culture among the study participants was "Hospital Handoffs and transitions" (19.2\%) revealing a problem in safe continuity of care, with a high possibility of losing important patient information that may affect the progress of medical condition, alter the desired outcome, and contribute to adverse events and near miss [24], thus, the efficient and effective transfer of patient care information from one hospital staff member to another is an essential element of positive safety 
culture [25]. Similar result of low positive responses of $24.6 \%$ was found by Aboul-Fotouh et al. [22].

Furthermore, the "non-punitive response to error" received an average low positive response of $20.6 \%$ of the study participants; however, events' reporting in a non-punitive environment is crucial for improving patient safety. This result was agreed on by Aboul-Fotouh et al. at $19.8 \%$, revealing that the health-care personnel are not at ease when it comes to reporting errors [22]. On the other hand, higher positive responses were found in other studies, the US hospitals (44\%) [26], Abdelhai and associates, 2012, with $33.3 \%$ [27] and the score in Lebanese Hospitals was $24.3 \%$ [28].

In the present study, the effect of the intervention on patient safety culture was investigated. The findings suggest that the intervention significantly improved some of the aspects of patient safety culture. This was synonymous to the study by Verbakel et al. [29]. As well as a case-control study performed in India by Amiri et al. to study the effect of an educational program on the attitudes of nurses toward patient safety, significant improvements were observed in 5 out of 12 dimensions in the experimental group [30].

In the current study, significant improvement occurred in two items of "safety climate," in the attitude toward personnel guidelines' knowledge and responsibility for patient safety, coinciding with Amiri et al.'s overall safety climate score, which could be explained by the significant increase in their knowledge of patient safety and their involvement in the program and raising their sense of responsibility toward incident reporting [30].

In addition to, three of the five items of management perception to patient safety were significantly improved. This can be explained by the fact that the ICU management team as well as the quality department team were involved in the program with reassurance and enhancing the trust of the healthcare personnel, a finding that is similar to Amiri's et al. study results in 2018 [30].

Improved management perception to patient safety together with teaching the health-care personnel to speak up, through incident reporting specially about near misses that were included in the study intervention might explain the significant improvement in "communication openness" dimension after the intervention and the differences between the current findings and those from previous studies. This finding was in line with the findings of a study by Andreoli et al. [31]. However, it was in contradiction with the results of two other studies, in which patient safety education and teamwork training of nurses and hospital staff did not improve their attitudes on communication openness [32], [33].

The item of "I have made errors that had the potential to harm patients" in the "overall perception of patient safety" dimension was significantly deteriorated, which might be explained by the increase in their knowledge and awareness of the quality of care that should be performed in their PICUs.

The use of the pertinent JCI IPSGs as a framework offers specific tools to improve patient safety to validate that these standards are being met, it addresses the day-to-day patient care issues [34].

Moving on in the pursuit to understand the baseline assessment of the patient safety situation in the PICUs' observation of patient safety practices and hospital measures according to $\mathrm{JCl}$ accreditation checklist was done.

Starting with the identification process of patients in the four PICUs, sometimes patients were not identified using two patient identifiers, and sometimes they were identified using their file number, as recommended by the $\mathrm{JCl}$ in 2016. All patients' identities were confirmed before performing diagnostic procedures, providing treatments, and performing other procedures. The PICUs do not have a documented process that ensures the correct identification of patients in special circumstances, such as the comatose patient or newborn who is not immediately named. In a study by Gray et al., $50 \%$ of the patients in the neonatal ICU were at risk of misidentification [35].

Regarding communication in the PICUs, verbal and telephone orders or test results were not documented and read back by the receiver and confirmed by the individual giving the order. The PICUs have defined critical values for each type of diagnostic test and to whom they are reported. Data from adverse events resulting from handover communications were not tracked and used to identify ways, in which handovers can be improved, and improvements are implemented. This came in accordance to the results obtained by Craig et al. in a study designed to strengthen handover communication in PICUs [24].

As for the high-alert medications safety, two of the PICUs have not yet identified in writing their list of high-alert medications or developed and implemented a process for their management. Three of the PICUs have a list of look-alike/sound-alike medications and developed and implemented a process for their management. However, all the four PICUs have yet to develop a process that prevents inadvertent administration of concentrated electrolytes to follow the guidelines of the $\mathrm{JCl}$ in 2016.

Although there is a committee for infection control in the hospital, yet the system required to reduce the risk of health-care acquired infections is still deficient. The hospital has adopted current evidence-based hand hygiene guidelines, the hospital implements a hand hygiene program throughout the hospital, handwashing, and hand disinfection procedures were not always used in accordance with hand hygiene guidelines throughout the hospital which was similar to the findings by Owens 
and Stoessel, where hand hygiene practices were not followed at all times by the health-care personnel [36].

Finally, regarding falls prevention, the PICUs are in the process of implementing a process for assessing all inpatients for fall risk and using assessment tools/ methods that are appropriate for the patients being served, however, it was not yet implemented till the end of this study. However, measures to reduce fall risk are implemented for all inpatients, situations, and locations within the PICUs, particularly those expected to be at risk by the physicians, for example, convulsing patients, including raising bedrails and adjusting the beds for the patients, and preventing slippery floors. In the study by Heafner et al., the lack of falls risk assessment was the reason to develop a tool to assess risk for falls in women in hospital obstetric units [37].

On examining the results of the end line assessment of the patient safety practices after this study intervention, four of the five studied goals improved significantly after the intervention. While only the falls prevention did not show improvement, as the rest of the standards of this goal should be met by implementing a fall risk assessment checklist in the PICUs, which was planned but not yet implemented up until the end of the current study.

A similar study to ours by Verbakel et al. found that patient safety practices improved significantly after administering of a patient safety culture questionnaire followed by a workshop [29]. Ragsdale also found similar results on implementing the $\mathrm{JCl}$ standards in an endoscopy unit in 2011 [38].

A recent study conducted in Portugal with the purpose of determining the impact of educational initiatives on the indicator for adherence to verification of patients' identification detected major improvements in the proposed intervention, with increased adherence overtime for up to $94.37 \%$ of the sample [39].

The success of the intervention to improve the practices in the PICUs can also be explained using employees' awareness-raising strategy and the fact that patient safety interventions with evidence of sincerity, commitment, and enthusiasm among senior leadership in the hospital about improving patient safety enjoyed a very high level of commitment, as they could link the program very clearly and explicitly to local need and that they saw it as helpful in providing a response to incidents [40].

\section{Conclusion and Recommendations}

The results of the current study led to the conclusion that patient safety knowledge, culture, and practice had much room for improvement in the hospital and that the strategies based on patient safety awareness-raising among health- care providers together with commitment and enthusiasm among senior leadership in the hospital can potentially improve compliance with practice and consequently lead to better patient safety, thus patient safety should be a top strategic priority for policy-makers, managers, leaders, and frontline staff of Cairo University Hospitals. Implementation of multifaceted interventional patient safety program is important for improving the compliance to patient safety standards including interval patient safety training programs for health-care personnel with continuous monitoring and performance indicators calculation as well as communication of the feedback to all staff members about patient safety performance being beneficial. Furthermore, incorporation of patient safety as a concept and approach in the educational curricula is recommended as well as training for medical students during their internship.

\section{Limitations of the study}

The sample in this study was limited to healthcare providers working in one pediatric teaching hospital in Egypt which limits the generalization of results to other teaching hospitals.

\section{References}

1. Systems Approach. In: Patient Safety Network. Rockville, MD: Agency for Healthcare Research and Quality; 2019. Available from: https://www.psnet.ahrq.gov/primers/primer/21. [Last accessed on 2019 Jul 23].

2. Leape L. Testimony before the President's Advisory Commission on Consumer Production and Quality in the Health Care Industry; 1997.

3. World Health Organization. Patient Safety Global Action on Patient Safety. Report by the Director-General. Geneva: World Health Organization; 2019. Available from: https://www.apps. who.int/gb/ebwha/pdf_files/WHA72/A72_26-en.pdf. [Last accessed on 2019 Jul 23].

4. Fitzsimons J, Vaughan D. Top 10 interventions in pediatric patient safety. Curr Treat Options Peds 2015;1:275-85. https:// doi.org/10.1007/s40746-015-0035-3

5. Wilson RM, Michel P, Olsen S, Gibberd RW, Vincent C, El-Assady $\mathrm{R}$, et al. Patient safety in developing countries: Retrospective estimation of scale and nature of harm to patients in hospital. BMJ. 2012;344:e832. https://doi.org/10.1136/bmj.e832 PMid:22416061

6. Workplace Health and Safety Queensland. Understanding Safety Culture. Brisbane: The State of Queensland; 2013. Available from: https://www.worksafe.qld.gov.au/data/assets/ pdf_file/0004/82705/understanding-safety-culture.pdf. [Last accessed on 2019 Jul 26].

7. Hellings J, Schrooten W, Klazinga N, Vleugels A. Challenging patient safety culture: Survey results. Int J Health Care Qual Assur. 2007;20(7):620-32. https://doi. org/10.1108/09526860710822752

PMid:18030963. 
8. Nieva V, Sorra J. Safety culture assessment: A tool for improving patient safety in health care organizations. Qual Saf Health Care. 2003;12:17-23. https://doi.org/10.1136/qhc.12.suppl_2.ii17

9. Reason J. The Human Contribution: Unsafe Acts, Accidents and Heroic Recoveries. Vol. 30. Ashgate Pub Ltd.; 2008. p. 200-10. https://doi.org/10.1201/9781315239125

10. Wheeler D, Wong DS, Thomas S., editors. Pediatric Critical Care Medicine. London: Springer-Verlag.

11. WHO Multi-professional Patient Safety Curriculum Guide; 2011. Available from: http://www.who.int/patientsafety/education/ curriculum/tools-download/en. [Last accessed on 2018 Nov 02].

12. Sexton JB, Helmreich RL, Neilands TB, Rowan K, Vella K, Boyden $J$, et al. The safety attitudes questionnaire: Psychometric properties, benchmarking data, and emerging research. BMC Health Serv Res. 2006;6:44. https://doi. org/10.1186/1472-6963-6-44

PMid:16584553

13. Elsous A, Akbarisari A, Rashidian A, Aljeesh Y, Radwan M, Abu Zaydeh H. Psychometric properties of an Arabic safety attitude questionnaire (short form 2006). Oman Med J. 2017;32(2):11523. https://doi.org/10.5001/omj.2017.21 PMid:28439381

14. Walton MM, Elliott SL. Improving safety and quality: How can education help? Med J Aust. 2006;184(S10):S60-4. PMid:16719739

15. Oliveira JL, Silva SV, Santos PR, Matsuda LM, Tonini NS, Nicola AL. Patient safety: Knowledge between multiprofessional residents. Einstein (Sao Paulo). 2017;15(1):50-7. https://doi. org/10.1590/s1679-45082017ao3871

PMid:28444089

16. Wami SD, Demssie AF, Wassie MM, Ahmed AN. Patient safety culture and associated factors: A quantitative and qualitative study of healthcare workers' view in Jimma zone Hospitals, Southwest Ethiopia. BMC Health Serv Res. 2016;16:495. https://doi.org/10.1186/s12913-016-1757-z PMid:27644960

17. Robson J, de Wet C, McKay J, Bowie P. Do we know what foundation year doctors think about patient safety incident reporting? Development of a Web based tool to assess attitude and knowledge. Postgrad Med J. 2011;87(1033):750-6. https:// doi.org/10.1136/pgmj.2011.117366

PMid:21803929

18. Flotta D, Rizza P, Bianco A, Pileggi C, Pavia M. Patient safety and medical errors: Knowledge, attitudes and behavior among Italian hospital physicians. Int J Qual Health Care. 2012;24(3):258-65. https://doi.org/10.1093/intqhc/mzs014 PMid:22490299

19. El-Sayed IH, Ryan S, Schell H, Rappazini R, Wang SJ. Identifying and improving knowledge deficits of emergency airway management of tracheotomy and laryngectomy patients: A pilot patient safety initiative. Int J Otolaryngol. 2010;2010:638742. https://doi.org/10.1155/2010/638742 PMid:20585351

20. Wachter RM. Patient safety at ten: Unmistakable progress, troubling gaps. Health Aff (Millwood) 2010;29(1):165-73. https:// doi.org/10.1377/hlthaff.2009.0785

PMid: 19952010

21. Aveling EL, Martin G, Armstrong N, Banerjee J, Dixon-Woods M. Quality improvement through clinical communities: Eight lessons for practice. J Health Organ Manag. 2012;26(2):15874. https://doi.org/10.1108/14777261211230754 PMid:22856174

22. Aboul-Fotouh AM, Ismail NA, Ez Elarab HS, Wassif GO. Assessment of patient safety culture among healthcare providers at a teaching hospital in Cairo, Egypt. East Mediterr Health J.
2012;18(4):372-7. https://doi.org/10.26719/2012.18.4.372 PMid:22768700

23. Alahmadi H. Assessment of patient safety culture in Saud Arabian hospitals. BMJ. 2010;338:342. https://doi.org/10.1136/ qshc.2009.033258

24. Craig R, Moxey L, Young D, Spenceley NS, Davidson MG. Strengthening handover communication in pediatric cardiac intensive care. Paediatr Anaesth. 2012;22(4):393-9. https://doi. org/10.1111/j.1460-9592.2011.03758.x PMid:22211700

25. Smaggus A, Weinerman AS. Handover: The fragile lines of communication. Can J Gen Int Med. 2015;10(4):15-9. https:// doi.org/10.22374/cjgim.v10i4.82

26. Profit J, Etchegaray J, Petersen LA, Sexton JB, Hysong SJ, Mei $\mathrm{M}$, et al. Neonatal intensive care unit safety culture varies widely. Arch Dis Child Fetal Neonatal Ed. 2012;97(2):F120-6. https://doi.org/10.1136/archdischild-2011-300635 PMid:21930691

27. Abdelhai R, Abdelaziz S., Ghanem N. Assessing patient safety culture and factors affecting it among health care providers at Cairo university hospitals. J Am Sci 2012;8(7):277-85.

28. El-Jardali F, Jaafar M, Dimassi H, Jamal D, Hamdan R. The current state of patient safety culture in Lebanese hospitals: A study at baseline. Int J Qual Health Care. 2010;22(5):386-95. https://doi.org/10.1093/intqhc/mzq047

PMid:20699233

29. Verbakel NJ, de Bont AA, Verheij TJ, Wagner C, Zwart DL. Improving patient safety culture in general practice: An interview study. Br J Gen Pract. 2015;65(641):e822-8. https://doi. org/10.3399/bjgp15x687865

PMid:26622035

30. Amiri M, Khademian Z, Nikandish R. The effect of nurse empowerment educational program on patient safety culture: A randomized controlled trial. BMC Med Educ. 2018;18(1):158. https://doi.org/10.1186/s12909-018-1255-6 PMid:29970054

31. Andreoli A, Fancott C, Velji K, Baker GR, Solway S, Aimone E, et al. Using SBAR to communicate falls risk and management in inter-professional rehabilitation teams. Healthc Q. 2010;13(Spec No):94-101.

32. AbuAIRub RF, Abu Alhijaa EH. The impact of educational interventions on enhancing perceptions of patient safety culture among Jordanian senior nurses. Nurs Forum. 2014;49(2):139 50. https://doi.org/10.1111/nuf.12067 PMid:24392690

33. Jones F, Podila P, Powers C. Creating a culture of safety in the emergency department: The value of teamwork training. J Nurs Adm. 2013;43(4):194-200. https://doi.org/10.1097/ nna.0b013e31828958cd

\section{PMid:23528684}

34. Joint Commission International. National Patient Safety Goals Effective January 1, 2016: Hospital Accreditation Program; 2016. Available from: https://www.jointcommission.org/assets/1/6/2016 _NPSG_HAP.pdf. [Last accessed on 2018 Nov 12]

35. Gray J, Ursprung R, Glodmann DA, Horbar J. Patient misidentification in the neonatal intensive care unit (NICU): Quantification of risk. Pediatr Res. 2004;55:519A.

36. Owens CD, Stoessel K. Surgical site infections: Epidemiology, microbiology and prevention. J Hosp Infect. 2008;70(Suppl 2):3-10.

PMid:19022115

37. Heafner L, Suda D, Casalenuovo N, Leach LS, Erickson V, Gawlinski A. Development of a tool to assess risk for falls in women in hospital obstetric units. Nurs Womens Health. 2013;17(2):98-107. https://doi.org/10.1111/1751-486x.12018 
PMid:23594322

38. Ragsdale JA. Validating patient safety in the endoscopy unit using thejointcommissionstandards. GastroenterolNurs2011;34(3):21823. https://doi.org/10.1097/sga.0b013e3181d6e4b1 PMid:21637087

39. Hemesath MP, dos Santos HB, Torelly EM, da Silveira Barbosa A de Magalhães AM. Educational strategies to improve adherence to patient identification. Rev Gaucha Enferm. 2015;36(4):43-8. https://doi.org/10.1590/1983-1447.2015.04.54289

PMid:26735757

40. Ozieranski P, Robins V, Minion J, Willars J, Wright J, Weaver S et al. Running a hospital patient safety campaign: A qualitative study. J Health Organ Manag. 2014;28(4):562-75. https://doi. org/10.1108/jhom-02-2013-0035

PMid:25241600 